\title{
A Review on Power Quality Monitoring and Its Controlling Techniques
}

\author{
Dr.D.Sivakumar ${ }^{1}$, J.P.Srividhya ${ }^{2}$, and T.Shanmathi ${ }^{3}$
}

\begin{abstract}
Power electronic device use in consumer increases and power quality monitoring suit essential. This survey paper reviews the various recently used devices such as Remote terminal unit, digital signal processor, microcontroller, etc that monitor the power quality issues. These devices monitor the different parameters of the power system and various events of the power quality using techniques such as Wavelet transform, S-transform, Radial Neural network, etc. The survey also discusses the communication techniques such as wireless, wire-based communication used for the transmission of data from the power system network to the system operator and control techniques such as Dynamic Voltage Restorer, Shunt Active Power Filter, etc. In addition to that, this paper discusses the monitoring of various power quality parameters in the transmission line using a motor load experimental setup. The SIGVIEW software captures the real time signal under different conditions and analyzes the various distributions of the signal such as frequency distribution, probability distribution, etc using MATLAB program.
\end{abstract}

Keywords-Flicker, Harmonics, Power Quality, Power Quality Monitoring, Voltage sag, Voltage swell.

\section{INTRODUCTION}

$\mathrm{I}_{\mathrm{N}}^{\mathrm{N}}$ recent years, the demand for electricity goes on increasing which in turn leads to the need for dynamic and complex electric power system with the utilization of renewable energy sources. In this increasing complex system, the Electric power quality (PQ), the fitness of electric power to consumers has become the great concern of customers, utilities, manufacturers, etc. The internal, external faults in the power system and usage of many power electronic devices greatly affect the power quality. There are two types of faults such as symmetrical and unsymmetrical faults usually occur in the power system that causes the power quality issues [1].In addition to these faults, usage of motor loads, switching of loads, etc. in industries causes PQ problems[2].

Moreover, electronic equipment and devices, such as microprocessors, microcontrollers, sensitive computerized equipment, telecommunications equipment, fluorescent lamps,

Dr.D.Sivakumar ${ }^{1}$ is with Easwari Engineering College as a Professor of Electronics and Communication Engineering Department, Chennai, TamilNadu, India.

J.P.Srividhya ${ }^{2}$ is a part time research scholar in Anna University, Chennai, TamilNadu, India.

T.Shanmathi ${ }^{3}$ is with SKP Engineering College as a student of M.E/Power System Engineering, Tiruvannamalai, TamilNadu, India.
CFLs, and other devices can also cause PQ problems in power system [3]. Due to these faults and usage of those devices mentioned above, the power quality issues arises such as voltage sag, voltage swell, harmonics, flicker, interruption, etc.[4], [5]. These issues greatly affect the system performance that may lead to system loss, safety, and economic problems and in some cases; it may result in system failure. Therefore, there is a need for an accurate and reliable monitoring and control of power system. Monitoring of power system provides us information about power flow and demand and helps to identify the causes and location of power system disturbances before they cause interruptions or disturbances. The next section discusses the several monitoring devices used with several techniques.

\section{PQ MONITORING TECHNIQUES}

The monitoring and controlling of power quality issues becomes very essential in order to maintain power system stability. There are various techniques available to monitor the various power quality issues such as sag, swell, harmonics, flicker, etc. Few of the techniques monitors the above issues as explained below.

\section{A. Detection and Classification of Power Quality Disturbances}

PQ disturbances cause very high damage to devices and equipments. The quick detection and solution for $\mathrm{PQ}$ disturbances will reduce the effect of those disturbances in the power system. One of the techniques used to detect and classify the PQ disturbances include Wavelet packet decomposition and Support vector machine. Wavelet packet decomposition carries out the signal analysis that decomposes both low frequency and high-frequency bands. The support vector machine receives the decomposed signal that classifies the PQ problems. The accuracy of this method is about $97.25 \%[6]$.

The Discrete Wavelet Transform (DWT) technique is a signal-processing tool that provides information about the transient signal in the time-frequency plane. The DWT denoises the distorted signal to obtain high signal-to-noise ratio and the de-noised signal classifies the PQ disturbances. The accuracy of this method is about $98.18 \%$ but the main disadvantage is the need of specific method such as standard resolution analysis for classification [7].

The Stockwell transform(S-transform) technique overcomes the above disadvantage, which generates contours mainly for categorizing PQ disturbances. High accuracy, best time, and frequency resolutions, possibility of real-time industrial 
implementation for detection of PQ problems, interpretation of power system disturbances and integration with digital energy meters are the advantages of this technique [8].

\section{B. Harmonic Detection Techniques}

In power system networks, the generation of harmonics and its existence in line are the problems that cause distortions in load. The non-linear loads inject the more amounts of harmonic currents into the line. Several techniques aroused to determine the magnitude of harmonics and to estimate the true harmonic injection of the customer. The paper [9] proposes a recurrent neural network solution to this problem. A recurrent neural network consists of input layer, hidden layer and output layer. RNN uses the back propagation through time (BPTT) training algorithm to distinguish between the load harmonics and supply harmonics. The disadvantage of using this method is mainly due to its slow convergence [9].

In order to overcome this problem, paper [10]proposes the radial-basis-function neural network (RBFNN) technique. RBFNN is a feed forward neural network that applies a local searching mechanism to perform curve fitting. RBFNN uses only half period of the measured signal to achieve satisfactory results and has high accuracy than BPN. However, the harmonics calculated are only in fewer amounts and it does not calculate interharmonics [10].

This work [11] proposes the harmonic estimation method that uses a single layer neural network called ADALINE (Adaptive Linear Neuron). The ADALINE calculates not only the harmonics but also the interharmonics. It uses the learning algorithm called variable step-size least mean square (VSLMS) algorithm that minimizes the error as shown in Fig.1.The Field programmable gate array device used to perform the PQ monitoring consists of ADALINE neural network. It has the advantages of reconfigurability, flexibility, parallelism, etc.

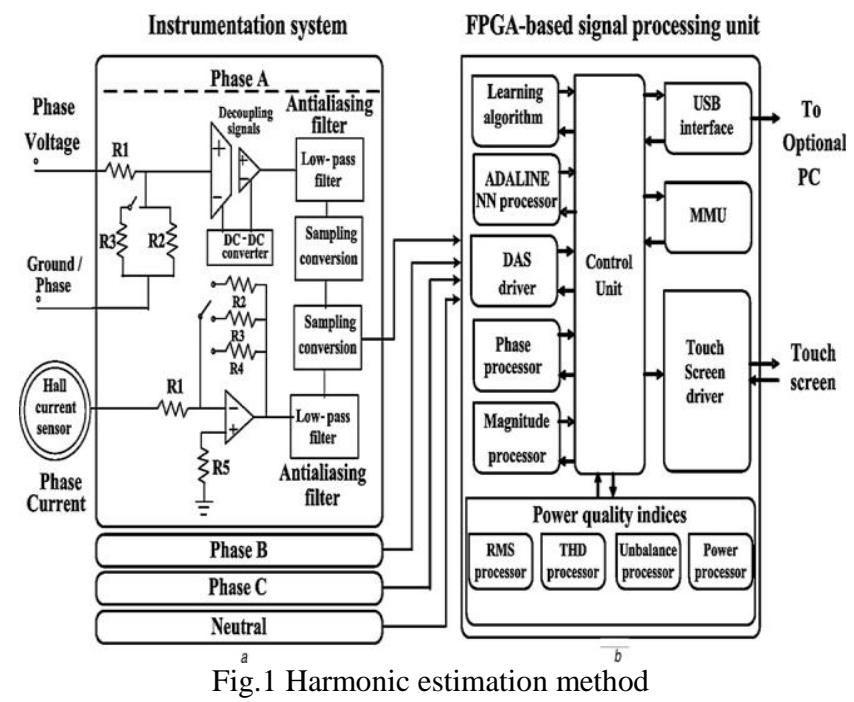

\section{Active and Reactive Power Estimation Techniques}

The power quality parameters such as active power and reactive power should be monitored regularly and accurately to provide a proper amount of power to the load. The analogue and digital signal processing (DSP) techniques measures the reactive power (RP) as proposed in [12].This technique uses the Walsh Transform (WT) based signal-processing algorithm to evaluate real and reactive power with the considerations of the voltage and the current waveforms without time delay between.

The Sample Shifting technique improves the efficiency of monitoring active and reactive power [13].A PLL based data acquisition system minimizes the measurement error. Microcontroller calculates active power from the values of the voltage and current samples. The Sample Shifting technique phase shifts the voltage and current samples by $90^{\circ}$ and the microcontroller calculates the reactive power from the phase shifted samples.

The techniques used above measures only the active and reactive power but not its harmonic components. In [14], the Remote Terminal Unit (RTU) monitors the power that consists of the microcontroller and serial communication as shown in Fig.2.The microcontroller measures sample values of voltage and current signals and estimates harmonic components of active and reactive powers using sample-shifting technique. The half-duplex mode of RS 485 serial communication communicates the estimated values with the Remote Monitoring Unit. This technique also finds out the DC power component and helps the electricity suppliers to decide the new tariff applied to the customers.

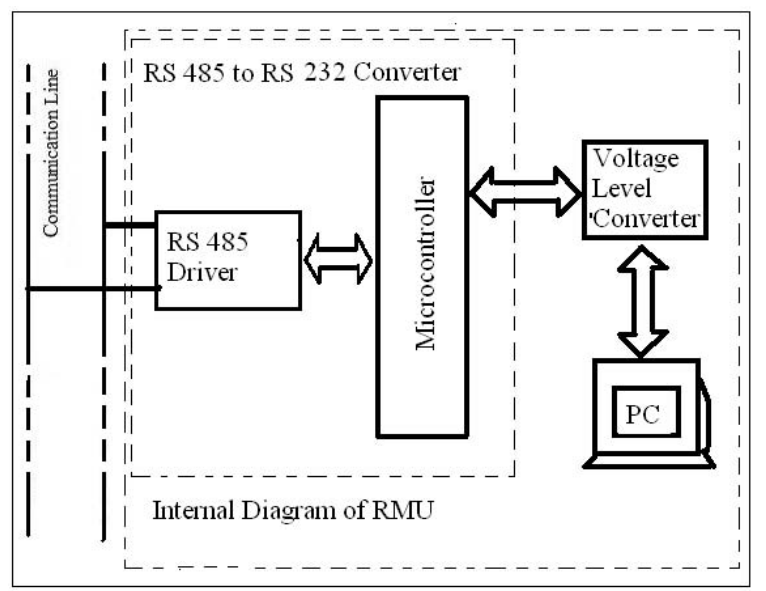

Fig.2 Remote Terminal Unit

\section{Flicker Source Detection Techniques}

Flicker is unsteadiness in the light intensity due to fluctuations in the voltage at the lamp terminals or due to its malfunction. There will be many loads contributing the flicker. There are many methods available to find out the dominating flicker source. An algorithm proposed in [15] uses the square demodulation method for calculating the direction of flicker source. In this algorithm, the demodulation produces the low frequency fluctuations arise in voltage and current signals. The band pass filter receives the output of demodulation that in turn produces the flicker power output. If the flicker power source has positive sign, then the direction of its propagation is from the generator to load and vice versa. The square demodulation has the disadvantage of generating 
additional low frequency components within the flicker frequency range.

The replacement of the envelope detector in place of square detector overcomes the above disadvantage. The envelope detector modulates the voltage and current signals. The low pass filter attenuates the frequency and harmonic components in the modulated voltage and this method is valid for any low frequency signal. The output of the low pass filter contains the magnitude and sign of flicker power that determines the dominating flicker source. The main disadvantage of this method is inaccurate flicker power calculation [16].

In the paper [17], the Flicker Power Algorithm based on Fast Fourier Transform (FFT) demodulation method overcomes the deficiency of inaccurate flicker power calculation. Flicker Power Algorithm follows the acceptable IEEE Flicker Meter standard. The FFT techniques used as a demodulation method to extract a flicker component on input signal without producing an unwanted frequency. This reliable technique separates the flicker components present in voltage and the current signal without producing the non-modulating component on the frequency spectrum.

\section{E. Frequency Estimation Techniques}

The frequency estimation problem has become the main issue in today's power system. There are various algorithm used for tracking frequencies. The Modified Newton algorithm proposed in [18] track frequencies which use the Ljung's ordinary differential equation approach for analysis. We reformulate the frequency estimation problem and derive a robust adaptive modified Newton algorithm for frequencies estimation. The linear prediction property of sinusoids develops the above algorithm to establish an unconstrained cost function for the adaptive frequencies estimation problem.

The new recursive Gauss-Newton method-based adaptive filter estimates the time-varying amplitude and phase angle of the voltage and current, in addition to the frequency value. This algorithm uses the unconstrained optimization of a weighted error cost function and the tuning of forgetting factor iteratively provides a robust tracking performance. The adaptive filter estimates the decaying dc components present in the signal along with its decay factor [19].

The Modified Recursive Gauss- Newton (MRGN) algorithm increases the accuracy of frequency estimation compared to previous method that includes both speed of convergence of the Newton algorithm and the gradient technique of Gauss method. This algorithm works with better accuracy for the time varying signal and for sudden changes in amplitude, phase, and frequency, harmonic components. This method neglects the off-diagonal elements of Hessian matrix to achieve faster calculation and has the advantages of high accuracy, minimizes error cost function and used for real- time calculations [20].

\section{COMMUNICATION PROTOCOLS}

In power system network, there are various devices available to monitor the parameters of the network such as voltage, current, frequency and the power quality events such as voltage sag, swell, harmonics, flicker, DC offset, etc. The monitored events communicate with the system operator through wire-based, wireless or using both technologies as explained in below section.

\section{A. Wireless Technologies}

The Wireless Power Quality/Energy and Facilities Monitoring System proposed in[21]use the Short Message Service (SMS), a means of sending short messages to and from mobile phones. The cost effective transmission media does not requires real-time connection between point-to- point or pointto-multipoint and it can operate in offline mode also. This technique does not transfer a high data volume such as waveform pattern and is preferred only for a simple message such as voltage dip percentage.

The various wireless communication technologies such as wireless LAN,WiMAX,3G/4G cellular, ZigBee, MobileFi, etc. proposed in [22] has the latest available data rates, distance coverage features and other important technology features. The earlier users ignored the wireless technology due to low data rates, interference related issues, security concerns, limited product availability, etc.

Zigbee communication module communicates the measured data of current and voltage to server module. The computer analyzes the measured data through some procedures [23]. Zigbee works on the low data rate with minimum power consumption and has the advantages of low-cost, low power consumption, etc.

The mobile communication transmits the data for monitoring and controlling the power system parameters in distributed generation [24]. The mobile communication uses the intelligent caching satellite femtocells technology to transmit data from reference network to base stations.

The wireless sensor networks used in most of the networks consumes more energy. The Mobile Sink Based Reliable and Energy Efficient Data Gathering technique for WSN proposed in [25] overcomes this disadvantage.

\section{B. Wired Technologies}

In [26], the server-router that has access to all substation data through the substation LAN has proposed instead of the RTU (Remote Terminal Unit)concept.

The MAX2990, a power line carrier communication module proposed in [27] adopts an OFDM (Orthogonal frequencydivision multiplexing) technology. OFDM is a kind of special multicarrier modulation technology mode used to retransmit the information and has the advantages of good communication performance, low cost, low error rate, easy installation, and high abilities of anti-interference.

The OPNET System-in-the-Loop communication module (SITL) proposed in [28] connects the simulation model to the live network hardware providing gateways or interfaces as shown in Fig.3.This SITL module provided with the specific network adaptor exchanges the packet with the external hardware through an Ethernet link. 


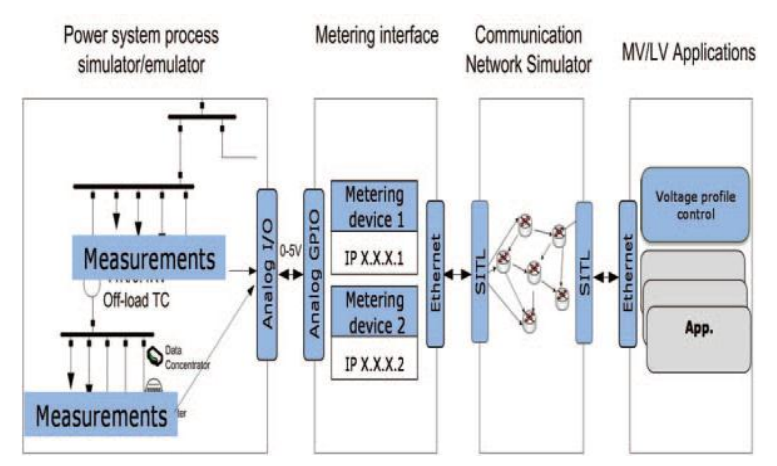

Fig.3 SITL communication module

\section{Hybrid Technologies}

The communication infrastructure design aspects for distributed control were proposed in [29] and analyze two cases of Active Network Management (ANM). This paper discussed both the advantages and disadvantages of wired and wireless technologies. The wired technologies such as Digital Subscriber Lines (DSL), optical fiber cable and power line carrier provide more reliability, capacity and security but are costly for large-scale deployment. The wireless technology will save installation costs with flexible configuration and fast deployment but with con- strained bandwidth and security.

The paper [30] proposes the design of hybrid communication network that includes both wire-based and wireless communication for large-scale wind turbines. The wind turbines use the Wi-Fi-based and Zigbee-based wireless communication technologies to communicate within the network and use the Ethernet switch to communicate the sensed data from the wind towers with the internal network.

Hierarchical communication network architecture for widearea management system (WAMS) proposed in [31] consists of three levels. The GPS (Global Positioning System) synchronizes the Phasor Measurement Units placed at the several wind power plants (WPP). The PMU measures the data and sends to the substation through the Ethernet switch. Each substation uses the synchronous optical network (SONET) links to communicate the received data with other substations.

\section{CONTROL TECHNIQUES}

The major power quality problems in the power system are voltage sag, swell, harmonics, flicker, etc. There are several techniques available to monitor these problems as discussed in Section I. The control of monitored disturbances improves the system performance. There are several methods/techniques used to mitigate those problems as discussed below.

\section{A. Voltage Sag \& Swell Mitigation Techniques}

One of the important issues in power system is voltage sag. Dynamic Voltage Restorer (DVR), a custom power device mitigates the sag, swell and maintains the load voltage constant as shown in Fig.4.PI controller and discrete PWM generator controls the DVR. The PI controller generates the signal for the PWM generator that in turn injects the voltage into the line for mitigation[32].

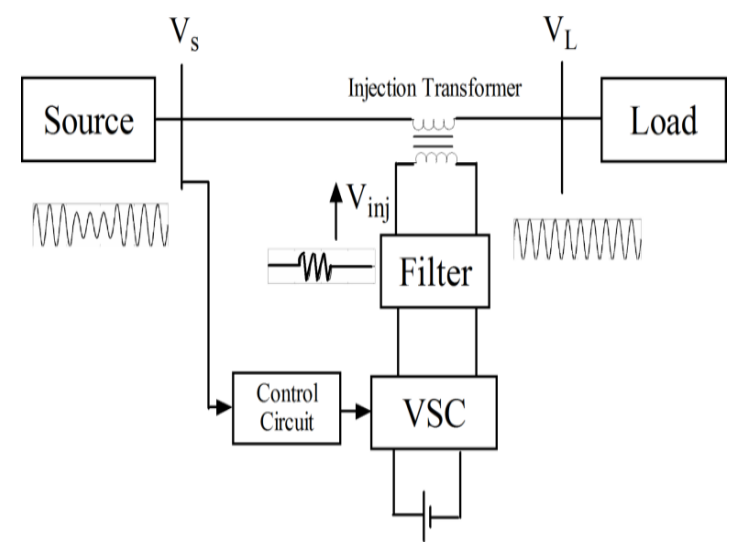

Fig.4 Control circuit of DVR

The hysteresis controller overcomes the disadvantages of PI controller [33] with the advantages like easy implementation, fast response, simple operation, etc. The two methods that generate the reference voltage in this paper are Fourier transform technique and Synchronous Reference Frame theory. These two methods detect the condition of voltage sag/swell and give the reference voltage. The difference between reference voltage and the injected voltage produces an error signal. The hysteresis controller receives the error signal as input for generating the gating pulse for IGBT used in voltage source converter.

\section{B. Harmonic Mitigation Techniques}

Harmonics is the major problem in the power system that causes many disturbances in the power system operation. There are various ways of mitigating the harmonics. One of the main methods is the use of filters: the active or passive filter. The paper [34] discusses the various types of passive filters such as Passive series filter, Passive shunt filter; Passive harmonic filters (single tuned and high pass filter).

In [35], The Shunt Active Power Filter mitigates the harmonics and the hysteresis current controller produces the gating signals for the inverter. Adaptive hysteresis current controller and fixed band current controller are the two types of hysteresis current controller available. The fixed band hysteresis current controller offers good accuracy, good stability, fast response, and simple operation.

\section{Flicker Mitigation Techniques}

Flicker is the fluctuations in the voltage waveform that causes quite disturbances in the power system network. The dynamic Volt/VAR control is one of the flicker mitigation techniques that dispatches the reactive power based on voltage fluctuations within the flicker frequency band [36].

In [37], a coordinated control of active and reactive power control mitigates the flicker contribution in the distributed wind generation. Active power control ensures the margin level of reactive power absorption for reducing the severity of flicker level. 


\section{RESULTS AND DISCUSSION}

This section discusses the monitoring of various power quality parameters such as sag, swell, harmonics in the transmission line using following setup. The $230 \mathrm{~V}$ power supply supplies the power to the Induction motor, which is acting as a load. The Toroidal coil traps and senses the signal from the line connecting supply and motor load. The connection from the Toroidal coil to the PC captures the signal flowing in the linesupplying load by the SIGVIEW software. The voltage regulator increases and decreases the voltage for measuring the signal during sag and swell condition.

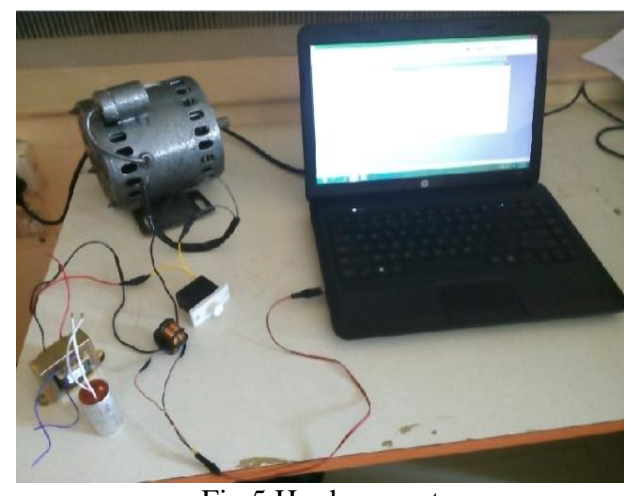

Fig.5 Hardware setup

The captured signals are then analyzed through the MATLAB program that produces the various distributions.

\section{Case 1: Normal condition}

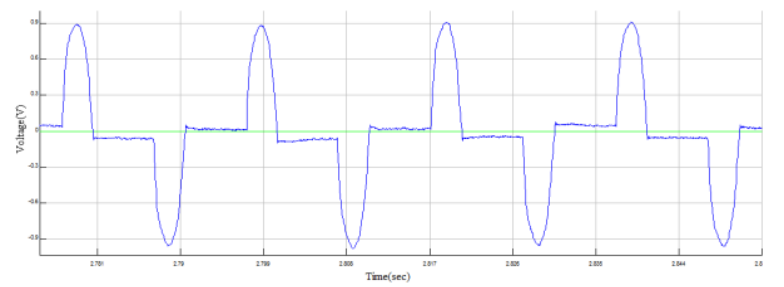

Fig.6 Waveform of normal signal

The Sigview software captures the $230 \mathrm{~V}$ signal for the limited duration of 10 seconds during normal condition without any disturbances. The Fig.6 shows the normalized waveform of the captured signal with the magnitude of $0.9 \mathrm{~V}$.

The MATLAB program produces the following distributions when the captured signal runs through it.

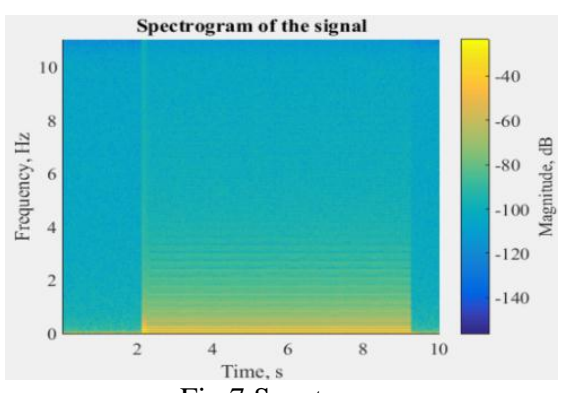

Fig.7 Spectrogram

The spectrogram is nothing but the distribution of frequencies present in the captured signal. It shows how the frequency in the signal distributes throughout the signal and varies from time to time. The vertical and horizontal axis shows the frequency and time respectively. In addition to that, Fig. 7 also shows the magnitude of the energy present in the signal which varies with time. The light region and dark region shows the low distribution and high distribution of energy in the signal.

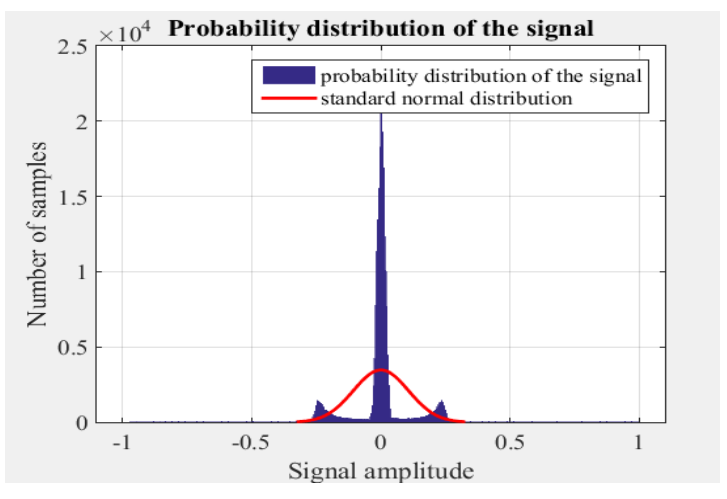

Fig.8 Probability Distribution

The probability distribution of the signal is nothing but the probability of random variables. The random variables here are the number of samples obtained from the signal. The main parameter used for this graph includes mean and standard deviation. The mean value is the average of the samples that determines the location of center of graph and standard deviation is variation of value from the mean value that determines the height of the graph. The mean and standard deviation obtained during the normal condition are 0.10648 and $2.4838 \mathrm{e}-05$.

\section{Case 2: During sag}

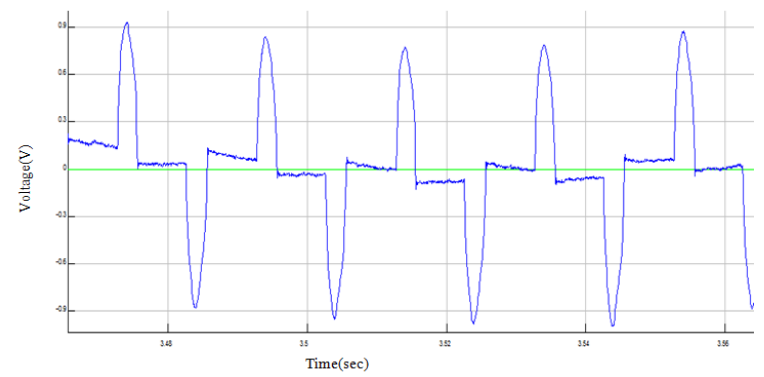

Fig.9 Signal obtained during sag

The above figure shows the signal captured during sag condition. The voltage regulator decreases the voltage in the line in order to create the sag condition. The normalized waveform has the magnitude of 0.85 that is less than the normal magnitude.

The MATLAB program produces the following frequency and probability distributions when the captured signal runs through it. 


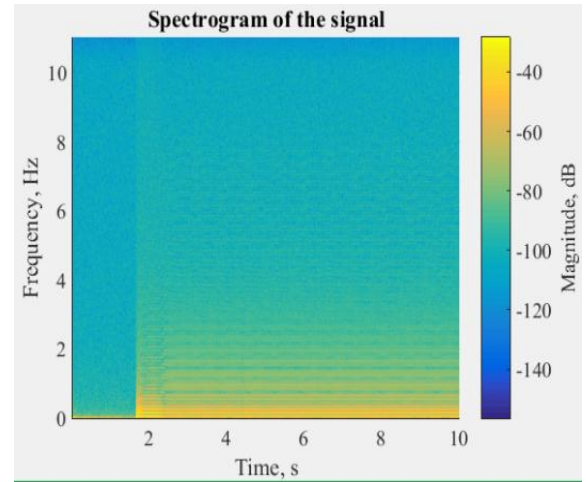

Fig.10 Spectrogram

The spectrogram obtained during sag condition indicates the less amount of energy distribution in the frequency signal as compared to normal signal.

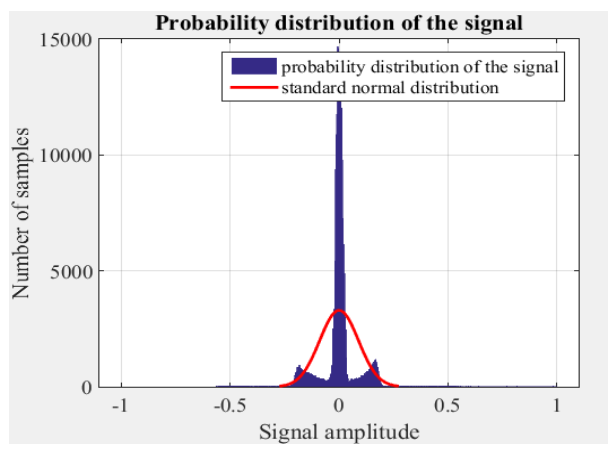

Fig.11 Probability distribution

The mean and standard deviation obtained during sag condition is 0.0000494 and 0.088918 that are the main factor for the probability distribution. The reduction in mean value shows that the sag had occurred.

\section{Case 3: During swell}

The voltage regulator increases the voltage in the line to create the swell condition. The waveform obtained during this condition has the magnitude of 0.95 greater than the normal magnitude.

The spectrogram obtained during this condition shows more amount of energy distribution in the signal. The mean and standard deviation to obtain the probability distribution graph are -0.000248 and 0.13506 .

\section{Case 4: During disturbances}

The insertion of capacitor and inductor for few seconds, for e.g. 3 or 4 seconds causes the disturbances in the waveform.

The spectrogram obtained during these insertions shows great variation in the energy distribution. During insertion of inductor, the energy distribution reduces. Alternatively, the energy distribution increases during insertion of capacitor.

The probability distribution graph also shows variation in extension of standard deviation in both cases. The mean and standard deviation obtained during insertion of inductor and capacitor are $-1.97 \mathrm{e}-05,-6.0527 \mathrm{e}-06$ and $0.09937,0.11026$ respectively.
Thus, this section discussed the variation of spectrogram, mean, and standard deviation and its probability distribution of the signal for different cases.

Therefore, this type of signal having different natures will be sent to the microcontroller for monitoring PQ parameters in the transmission line.

\section{FUTURE WORK}

The techniques discussed in Section I need a separate device for monitoring: sag, swell, harmonics, flicker, etc. The new device called Multipurpose Platform device that uses the recently developed microcontroller namely MSP430G2553, a reliable, portable, low cost and low power consumption device performs all the functions in one device itself, will be developed as future work. The communication protocol will be an Internet of Things (IoT) in order to monitor and analyze the power quality issues very quickly anywhere within the network. Harmonics, an important issue among the power quality issues will be quickly monitored and analyzed by using the Pan Tompkins algorithm that was previously used only in biomedical field. This monitored harmonics can be controlled by using DSTATCOM, one of the FACTS devices.

\section{CONCLUSION}

Power quality is a major concern in today's power system network. This survey discussed the recent methodologies or techniques used to monitor the power quality events and parameters, the different technologies used for communication and controlling techniques for different power quality issues. This survey also discussed the various distributions present in the transmission line signal such as spectrogram, probability distribution signal under normal, sag, swell condition and during disturbances using SIGVIEW and MATLAB software.

\section{ACKNOWLEDGMENT}

This work was supported by Prof.Dr.N.R.Shanker, M.Tech., Ph.D., Manager-(Research \&Development), Avadi, Chennai.

\section{REFERENCES}

[1] Disturbance Analysis for Power Systems , First Edition. Mohamed A. Ibrahim. Ó 2012 Mohamed A. Ibrahim. Published 2012 by John Wiley \& Sons, Inc. 33," pp. 33-84.

[2] A. El Mofty and K. Youssef, "Industrial Power Quality Problems," no. 482, pp. 18-21, 2001. http://dx.doi.org/10.1049/cp:20010757

[3] A. M. Blanco, R. Stiegler, and J. Meyer, "Power quality disturbances caused by modern lighting equipment (CFL and LED)," 2013 IEEE Grenoble Conf., pp. 1-6, 2013. http://dx.doi.org/10.1109/PTC.2013.6652431

[4] S. H. Laskar, "Power Quality Issues and Need of Intelligent PQ Monitoring in the Smart Grid Environment," vol. 2, no. 9, pp. 63-69, 2012.

[5] S. Ali, "A Research Review of Power Quality Problems in Electrical Power System," vol. 2, no. 2, pp. 88-93, 2012.

[6] W. Tong, X. Song, J. Lin, and Z. Zhao, "Detection and Classification of Power Quality Disturbances Based on Wavelet Packet Decomposition and Support Vector Machines," 2006 8th Int. Conf. Signal Process., vol. 4, 2006. http://dx.doi.org/10.1109/icosp.2006.346074

[7] L. C. Saikia, S. M. Borah, and S. Pait, "Detection and classification of power quality disturbances using wavelet transform, fuzzy logic and 
neural network,” 2010 Annu. IEEE India Conf., no. November 2009, pp. $1-5,2010$.

http://dx.doi.org/10.1109/indcon.2010.5712674

[8] M. J. B. Reddy, D. K. Mohanta, and K. Sagar, "A multifunctional realtime power quality monitoring system using Stockwell transform," IET Sci. Meas. Technol., vol. 8, no. 4, pp. 155-169, 2014.

http://dx.doi.org/10.1049/iet-smt.2013.0091

[9] J. Mazumdar and R. G. Harley, "Backpropagation Through Time Algorithm to Estimate Nonlinear Load Harmonic Currents," vol. 55, no. 9, pp. 3484-3491, 2008.

[10] G. W. Chang, C. Chen, and Y. Teng, "Radial-Basis-Function-Based Neural Network for Harmonic Detection," vol. 57, no. 6, pp. 2171-2179, 2010.

[11] M. Valtierra-rodriguez, R. D. J. Romero-troncoso, A. Garcia-perez, D. Granados-lieberman, and R. A. Osornio-rios, "Reconfigurable instrument for neural-network- based power-quality monitoring in 3phase power systems," vol. 7, no. October 2012, pp. 1498-1507, 2013.

[12] A. N. Abiyev, "A new digital signal processing based approach for evaluation of reactive power and energy in power distribution systems," 2007 Innov. Inf. Technol. Vols1 2, pp. 422-426, 2007.

[13] R. Saha, "Problems Associated with Active and Reactive Power Measurement using a State-of-the-art Technique and Its Remedy," vol. 1, no. 1, pp. 1-4, 2010.

[14] R. Saha, "Remote Monitoring for Power Quality Analysis of Distribution System," pp. 402-406, 2014. http://dx.doi.org/10.1109/ciec.2014.6959119

[15] P. G. V Axelberg and M. H. J. Bollen, "An Algorithm for Determining the Direction to a Flicker Source," vol. 21, no. 2, pp. 755-760, 2006.

[16] P. G. V Axelberg, M. H. J. Bollen, I. Y. Gu, and S. Member, "Trace of Flicker Sources by Using the Quantity of Flicker Power," vol. 23, no. 1, pp. 465-471, 2008.

[17] N. F. Jamaludin, "The Used of Fast-Fourier Transform ( FFT ) Demodulation for Flicker Source Identification," no. March, pp. 537$542,2014$.

http://dx.doi.org/10.1109/peoco.2014.6814487

[18] J. Yang, H. Xi, and W. Guo, "Robust Modified Newton Algorithm for Adaptive Frequency Estimation," vol. 14, no. 11, pp. 879-882, 2007.

[19] P. K. D. K. R. K. M. Padhee, "Fast recursive Gauss - Newton adaptive filter for the estimation of power system frequency and harmonics in a noisy environment," no. September 2010, 2011.

[20] S. Sontakke, "Novel Method for Estimation of PQ Indices in Microgrids," pp. 1159-1163, 2013. http://dx.doi.org/10.1109/iceets.2013.6533550

[21] P. K. Lee and L. L. L. A. I. Fieee, "A Practical Approach To Wireless Power Quality, Energy And Facilities Monitoring System,” pp. 1-3, 2008.

[22] P. P. Parikh, S. Member, M. G. Kanabar, and S. Member, "Opportunities and Challenges of Wireless Communication Technologies for Smart Grid Applications," no. Cc, 2010.

[23] N. Javaid, A. Sharif, A. Mahmood, S. Ahmed, U. Qasim, and Z. A. Khan, "Monitoring and Controlling Power using Zigbee Communications."

[24] B. N. Abramovich, Y. A. Sychev, and V. B. Prokhorova, "The Application of Modern Information Technologies for Power Monitoring and Control in Conditions of Distributed Generation."

[25] P. Madhumathy and D. Sivakumar, "Mobile Sink Based Reliable and Energy Efficient Data Gathering Technique for WSN," vol. 14, no. 12,

[26] pp. 78-85, 2014.

[27] A. Bose, "Smart Transmission Grid Applications and Their Supporting Infrastructure," vol. 1, no. 1, pp. 11-19, 2010.

[28] J. Guo, S. Su, and C. Fu, "Research on Power Quality Monitoring System based on low-voltage PLC Technology," pp. 0-3.

[29] M. Armendariz, M. Chenine, and A. Al-hammouri, "A Co-Simulation Platform for Medium / Low Voltage Monitoring and Control applications," 2014.

[30] Q. Yang, J. A. Barria, T. C. Green, and S. Member, "Communication Infrastructures for Distributed Control of Power Distribution Networks," pp. 1-13.

[31] M. A. Ahmed and Y. Kim, "Hybrid Communication Network Architectures for Monitoring Large-Scale Wind Turbine," vol. 8, 2013.

[32] D. Kim and Y. Kim, "Design and Performance Evaluation of Hierarchical Communication Network for Wide Area Measurement System," pp. 2-6, 2011.
[33] S. Hazarika, S. S. Roy, R. Baishya, and S. Dey, "Application of Dynamic Voltage Restorer in Electrical Distribution System for Voltage Sag Compensation," pp. 30-38, 2013.

[34] A. I. Pathan, S. S. Vanamane, and R. H. Chile, "Different control techniques of Dynamic Voltage Restorer for power quality problems," 2014 First Int. Conf. Autom. Control. Energy Syst., pp. 1-6, 2014. http://dx.doi.org/10.1109/aces.2014.6808019

[35] K. K. Srivastava, S. Shakil, and A. V. Pandey, "Harmonics \& Its Mitigation Technique by Passive Shunt Filter," Int. J. Soft Comput. Eng., vol. 3, no. 2, pp. 325-331, 2013.

[36] A. K. Sharma, "Power System Harmonic Reduction using Shunt Active Filter," pp. 935-939, 2014.

[37] M. Ammar and G. Joós, "Coordinated Active / Reactive Power Control for Flicker Mitigation in Distributed Wind Power," pp. 3161-3167, 2012.

http://dx.doi.org/10.1109/ecce.2012.6342350

[38] D. Mascarella, P. Venne, D. Guérette, and G. Joos, "Flicker Mitigation via Dynamic Volt / VAR Control of Power Electronic Interfaced WTGs," vol. 8977, no. c, pp. 1-8, 2015

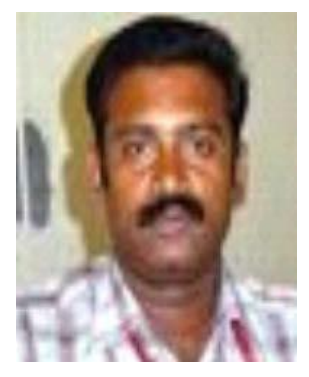

D. Sivakumar received the Bachelor's degree in ECE from Madras University, Post graduation in Instrumentation from Annamalai University and Ph.D. degree from Anna University, Chennai. He has 17 years of teaching and research experiences in various reputed engineering colleges. $\mathrm{He}$ is currently a Professor in the Department of ECE at Easwari Engineering College, Chennai. $\mathrm{He}$ has published more than 11 research papers in leading international and national journals and more than 24 research papers in leading international and national conferences. His research interests include Mobile Computing, MANET, Wireless Sensor Networks, Parallel and Distributed Computing.

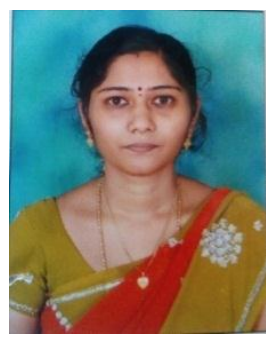

J.P.Srividhya is a part time research scholar in Anna University. She is working as an Assistant Professor, Department of Electrical and Electronics Engineering at SKP Engineering College, Tiruvannamalai. She received her Bachelor and Master degree from Anna University. She has a working experience of 10 years in teaching. Currently, She is pursuing her Ph.D. in the area of Power System Monitoring. She has published papers in national and international conferences. Her area of interests are Power system monitoring,

Electrical machines.

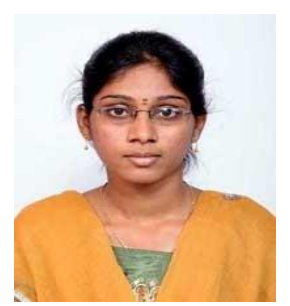

T.Shanmathi is currently doing her M.E in Power System engineering in SKP Engineering College, Tiruvannamalai. A. She received her Bachelor degree in Electrical and Electronics Engineering in SKP Engineering College from Anna University, Chennai in 2014. Her area of interests are Power system Monitoring, Power Quality, Soft computing. 